\title{
Docosahexaenoic acid has influence on action potentials and transient outward potassium currents of ventricular myocytes
}

\author{
Ru-xing Wang1 , Xiao-rong Li*1, Tao Guo², Li-ping Sun'1, Su-xia Guo'1, Zhen-Yu Yang ${ }^{1}$, Xiang-Jun Yang ${ }^{3}$ and Wen- \\ ping Jiang 3
}

\begin{abstract}
Background: There are many reports about the anti-arrhythmic effects of $\omega-3$ polyunsaturated fatty acids, however, the mechanisms are still not completely delineated. The purpose of this study was to investigate the characteristics of action potentials and transient outward potassium currents $\left(\left.\right|_{\text {to }}\right)$ of Sprague-Dawley rat ventricular myocytes and the effects of docosahexaenoic acid (DHA) on action potentials and $I_{\text {to. }}$.

Methods: The calcium-tolerant rat ventricular myocytes were isolated by enzyme digestion. Action potentials and $I_{\text {to }}$ of epicardial, mid-cardial and endocardial ventricular myocytes were recorded by whole-cell patch clamp technique.

Results: 1. Action potential durations (APDs) were prolonged from epicardial to endocardial ventricular myocytes $(P<$ 0.05). 2. I to current densities were decreased from epicardial to endocardial ventricular myocytes, which were $59.50 \pm$ $15.99 \mathrm{pA} / \mathrm{pF}, 29.15 \pm 5.53 \mathrm{pA} / \mathrm{pF}$, and $12.29 \pm 3.62 \mathrm{pA} / \mathrm{pF}$, respectively at $+70 \mathrm{mV}$ test potential $(P<0.05)$. 3. APDs were gradually prolonged with the increase of DHA concentrations from $1 \mu \mathrm{mol} / \mathrm{L}$ to $100 \mu \mathrm{mol} / \mathrm{L}$, however, APDs changes were not significant as DHA concentrations were in the range of $0 \mu \mathrm{mol} / \mathrm{L}$ to $1 \mu \mathrm{mol} / \mathrm{L}$. 4. t $_{\text {to }}$ currents were gradually reduced with the increase of DHA concentrations from $1 \mu \mathrm{mol} / \mathrm{L}$ to $100 \mu \mathrm{mol} / \mathrm{L}$, and its half-inhibited concentration was $5.3 \mu \mathrm{mol} / \mathrm{L}$. The results showed that there were regional differences in the distribution of action potentials and $\mathrm{I}_{\mathrm{to}}$ in rat epicardial, mid-cardial and endocardial ventricular myocytes. APDs were prolonged and $I_{\text {to }}$ current densities were gradually reduced with the increase of DHA concentrations.
\end{abstract}

Conclusion: The anti-arrhythmia mechanisms of DHA are complex, however, the effects of DHA on action potentials and $I_{\text {to }}$ may be one of the important causes.

\section{Background}

Fatty acids, especially polyunsaturated fatty acids (PUFAs), play an important role in life and death of cardiac cells. Reasons are as follow: 1. they are essential fuels for mechanical, electrical, and synthetic activities of the heart; 2. their levels are abnormally high in an ischemia followed by a reperfusion; and 3. dietary fish oil is apparently beneficial for heart function [1,2]. Therefore, the beneficial effects of PUFAs on cardiovascular diseases, such as fish oil, have been reported, and the effects of

* Correspondence: ruxingw@sina.com.cn

1 Department of Cardiology, Affiliated Hospital of Nanjing Medical University in Wuxi and People's Hospital of Wuxi City, Wuxi 214023, China

Full list of author information is available at the end of the article
PUFAs on anti-arrhythmias and prevention of sudden death have been highlights [3-6]. It has been reported that PUFAs have the roles of anti-arrhythmias and prevention of malignant ventricular arrhythmias, however, the mechanisms of which are still not completely delineated $[7,8]$.

$\omega-3$ PUFAs mainly include docosahexaenoic acid (DHA) and eicosapentaenoic acid (EPA). More attentions have been paid to their beneficial effects on cardiovascular diseases in recent years, especially in their antiarrhythmias and prevention of sudden cardiac death [913]. However, most of these studies are clinical trials, and the mechanisms of which are still not completely known. To investigate the mechanisms of $\omega-3$ PUFAs on anti- 
arrhythmias and prevention of sudden cardiac death $[1,8]$, we observed the effects of DHA on action potentials and transient outward potassium currents $\left(\mathrm{I}_{\mathrm{to}}\right)$ of Sprague-Dawley rat ventricular myocytes by whole-cell patch clamp technique in this study. The results may provide some experimental evidences for rational applications of $\omega-3$ PUFAs to prevent and treat arrhythmias in clinical practice.

\section{Methods}

\section{Major experimental instruments}

The instruments used were: MultiClamp 700B patch clamp amplifier (Axon Instruments, USA), D/A and A/D converter (DigiData 1322, Axon Instruments, USA), Pclamp 9.0 pulse software (Axon Instruments, USA), MP-285 motorized micromanipulator (Sutter Instruments, USA), IX71 inverted microscope (Olympus, Japan), SA-OLY/2 and DH-35 culture dish heater (Warner Instruments, USA), P-97 micropipette puller (Sutter Instruments, USA).

\section{Reagents, solutions and drugs}

The reagents, solutions and drugs used were: DHA (Sigma, USA), molecular weight 328.5, $100 \mathrm{mmol} / \mathrm{L}$ stock solution was prepared by being dissolved in absolute ethanol and protected from light in refrigerator at $-20^{\circ} \mathrm{C}$. The experimental concentration of DHA was obtained by dilution of stock solution before each experiment. Action

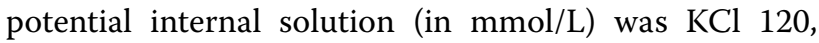
$\mathrm{CaCl}_{2} 1, \mathrm{MgCl}_{2}$ 5, $\mathrm{Na}_{2}$ ATP 5, EGTA 11, HEPES 10, glucose 11, pH 7.3 adjusted with $\mathrm{KOH}$. Action potential external solution was Tyrode's solution [14]. $\mathrm{I}_{\text {to }}$ external solution (in $\mathrm{mmol} / \mathrm{L}$ ) was $\mathrm{NaCl} 140, \mathrm{KCl} 4, \mathrm{CaCl}_{2} 1.5$, $\mathrm{MgCl}_{2} 1, \mathrm{CdCl}_{2}$ 0.5, HEPES 5, glucose 10, pH 7.4 adjusted with $\mathrm{NaOH}$. I to internal solution (in $\mathrm{mmol} / \mathrm{L}$ ) was $\mathrm{KCl}$ 140, $\mathrm{MgCl}_{2}$ 1, $\mathrm{K}_{2}$ ATP 5, EGTA 5, HEPES 10, pH 7.4 adjusted with $\mathrm{KOH}$. $\mathrm{KB}$ solution (in $\mathrm{mmol} / \mathrm{L}$ ) was L-Glutamic acid 50, $\mathrm{KCl} 40, \mathrm{KH}_{2} \mathrm{PO}_{4}$ 20, Taurine 20, $\mathrm{MgCl}_{2} 3$, $\mathrm{KOH}$ 70, EGTA 0.5, HEPES 10, glucose 10, pH 7.4 adjusted with $\mathrm{KOH}$.

\section{Cell isolation}

The investigation was approved by our institute ethics committee and conformed to the Guide for the Care and Use of Laboratory Animals published by the US National Institutes of Health (NIH publication No. 85-23, revised 1996). Healthy Sprague-Dawley rats of either sex, aged 812 weeks and weighing approximately $200 \mathrm{~g}$, were provided by the Experimental Animal Center of Soochow University (Suzhou, China). Animals were anesthetized with pentobarbital sodium intraperitoneally (i.p.), Hearts were removed and retrograde perfusion through the aorta was performed as described [15]. After retrograde perfusion was finished, epicardial, mid-cardial, and endocardial ventricular myocardium were obtained respectively by cutting with eye scissor and plyer. Isolated cells were kept at room temperature in $\mathrm{KB}$ solution and used within $6 \mathrm{hr}$; only relaxed, striated, and rod-shaped cells were used.

\section{Recordings of action potentials and $\mathrm{I}_{\text {to }}$ with and without DHA}

Currents in whole-cell voltage clamp configuration were recorded following the method of Hamill et al [16]. Myocytes were transferred to a $1 \mathrm{ml}$ chamber (DH-35 culture dish heater, Warner Instruments, USA) containing external solution placed on the stage of an inverted microscope. The chamber was continuously perfused at a rate of $1-2 \mathrm{ml} / \mathrm{min}$ with external solution. Electrodes were prepared from borosilicate glass (Clark Instruments, UK) using P-97 micropipette puller with resistances typically between 2 and $4 \mathrm{M} \Omega$ when filled with internal solution. Whole-cell voltage-clamp experiments were performed with MultiClamp 700B amplifier. Whole-cell capacitance and series resistance were compensated by $60-80 \%$. Experiments were performed at $36-37^{\circ} \mathrm{C}$. Voltage clamp pulses were generated via an IBM-compatible computer connected to Digidata 1322. Data acquisition and analyses were performed using pCLAMP software. To obtain action potentials, $5 \mathrm{~ms}$ depolarizing pulse with $900 \mathrm{pA}, 1$ $\mathrm{Hz}$ in current-clamp configuration was applied. DHA at $0.01 \mu \mathrm{mol} / \mathrm{L}, 0.1 \mu \mathrm{mol} / \mathrm{L}, 1 \mu \mathrm{mol} / \mathrm{L}, 10 \mu \mathrm{mol} / \mathrm{L}$, and 100 $\mu \mathrm{mol} / \mathrm{L}$ was perfused for $10 \mathrm{~min}$ respectively to observe the influence on action potential durations (APDs). To obtain $\mathrm{I}_{\mathrm{to}}, 600 \mathrm{~ms}$ depolarizing pulses in the range $-40 \mathrm{mV}$ to $+70 \mathrm{mV}$ were applied to the ventricular myocytes every $5 \mathrm{~s}$ in $+10 \mathrm{mV}$ increment from $-40 \mathrm{mV}$ holding potential (HP). Recordings of action potentials and $\mathrm{I}_{\text {to }}$ were performed at physiological temperature range $\left(36-37^{\circ} \mathrm{C}\right)$. DHA at various concentrations was applied to investigate the effects on $\mathrm{I}_{\text {to }}$.

\section{Statistical analysis}

Continuous variables were expressed as mean \pm standard error $(\bar{x} \pm$ se). SPSS11.5 (SPSS Inc, Chicago, Illinois, USA) was used for statistical analysis. Comparisons among groups were performed by repeated measurement analysis of variance (ANOVA) and least-significant difference contrast. Control and drug data for individual groups were compared by Paired $t$-test. $P \leq 0.05$ was considered significant. OriginPro 7.5 software (OriginLab, USA) was utilized to calculate the half-inhibited concentration $\left(\mathrm{IC}_{50}\right)$. 


\section{Results}

Characteristics of action potentials and $\mathrm{I}_{\text {to }}$ of rat ventricular myocytes

Action potentials of epicardial, mid-cardial and endocardial ventricular myocytes were recorded respectively with action potential stimulus protocol. The action potential morphologies were different in epicardial, mid-cardial and endocardial ventricular myocytes (Figure 1). $\mathrm{APD}_{25}$, $\mathrm{APD}_{50}$, and $\mathrm{APD}_{90}$ were gradually prolonged from epicardial to endocardial ventricular myocytes. Table 1 showed APDs' variations in myocytes of different layers; however, maximal velocity of action potential depolarization (Vmax), amplitude (APA), and overshoot (OS), didn't have remarkable changes in epicardial, mid-cardial and endocardial ventricular myocytes (Table 2).

$\mathrm{I}_{\text {to }}$ current tracings at various test potentials were elicited by $600 \mathrm{~ms}$ depolarization in the range of $-40 \mathrm{mV}$ to $+70 \mathrm{mV}$ pulses applied to the ventricular myocytes every $5 \mathrm{~s}$ in $+10 \mathrm{mV}$ increments from $-40 \mathrm{mV} \mathrm{HP}$. The representative current tracings were shown in figure 2. The current densities of epicardial, mid-cardial and endocardial ventricular myocytes at $+70 \mathrm{mV}$ were $59.50 \pm 15.99 \mathrm{pA} /$ $\mathrm{pF}, 29.15 \pm 5.53 \mathrm{pA} / \mathrm{pF}$, and $12.29 \pm 3.62 \mathrm{pA} / \mathrm{pF}$, respectively.

The current-voltage curves of $\mathrm{I}_{\text {to }}$ were plotted with current densities at each test potential (Figure 3). The threshold potential of $I_{\text {to }}$ channel opening was $-30.3 \pm 2.8$ $\mathrm{mV}$, i.e., $\mathrm{I}_{\text {to }}$ channel began to activate at more than $-30 \mathrm{mV}$. $\mathrm{I}_{\text {to }}$ currents were gradually enhanced with the increase of test potentials. The activation of $I_{\text {to }}$ channel was very rapid, and only needed to about $10 \mathrm{~ms}$, nonetheless, its inactivation was relatively slow. The time constants of epicardial, mid-cardial, and endocardial ventricular myocytes were almost the same at each test potential. They were $31.8 \pm 1.7 \mathrm{~ms}, 32.9 \pm 2.4 \mathrm{~ms}$, and $33.2 \pm 2.9 \mathrm{~ms}$, respectively, at $+70 \mathrm{mV}$ test potential $(P>0.05)$.

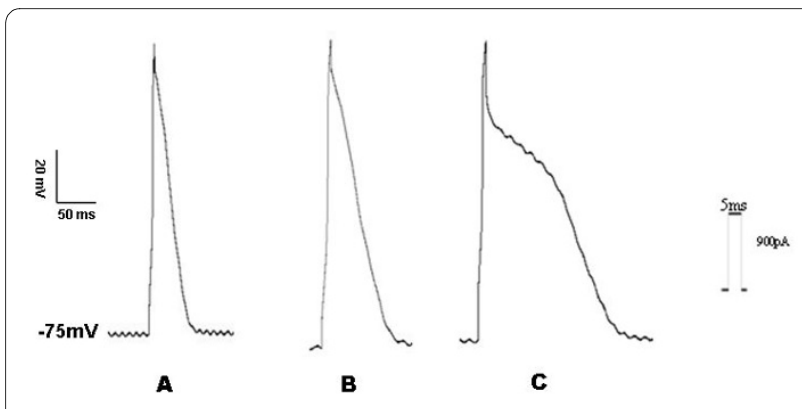

Figure 1 Action potential morphologies of rat ventricular myocytes: $A, B$ and $C$ were action potentials in epicardial, mid-cardial and endocardial ventricular myocytes, respectively. Action potential durations were gradually increased from epicardial ventricular myocytes to endocardial ventricular myocytes.

\section{Effects of DHA on action potentials}

DHA at $0.01 \mu \mathrm{mol} / \mathrm{L}, 0.1 \mu \mathrm{mol} / \mathrm{L}, 1 \mu \mathrm{mol} / \mathrm{L}, 10 \mu \mathrm{mol} / \mathrm{L}$, and $100 \mu \mathrm{mol} / \mathrm{L}$ was applied on epicardial ventricular myocytes, respectively. The results showed that: (1) APDs were gradually prolonged with the increase of DHA, whereas APDs' changes were not significant at low concentration of DHA $(<1 \mu \mathrm{mol} / \mathrm{L})$. The prolongation of $\mathrm{APD}_{25}, \mathrm{APD}_{50}$, and $\mathrm{APD}_{90}$ was less than $15 \%$ compared with the control $(0 \mathrm{~min})$ when $0.1 \mu \mathrm{mol} / \mathrm{L}$ DHA was applied (Figure 4). ? APDs were prolonged in a concentration-dependent manner when DHA concentrations were more than $1 \mu \mathrm{mol} / \mathrm{L} . \mathrm{APD}_{25}, \mathrm{APD}_{50}$, and $\mathrm{APD}_{90}$ were 7.7 $\pm 2.0 \mathrm{~ms}, 21.2 \pm 3.5 \mathrm{~ms}$, and $100.1 \pm 9.8 \mathrm{~ms}$ respectively when $10 \mu \mathrm{mol} / \mathrm{L} \mathrm{DHA}$ was used at $5 \mathrm{~min}$ (Figure $5 \mathrm{C}$ ). $\mathrm{APD}_{25}, \mathrm{APD}_{50}$, and $\mathrm{APD}_{90}$ were $15.2 \pm 4.0 \mathrm{~ms}, 45.7 \pm 6.8$ $\mathrm{ms}$, and $215.6 \pm 15.7 \mathrm{~ms}$ respectively when $100 \mu \mathrm{mol} / \mathrm{L}$ DHA was utilized at 5 min (Figure 5D), which was significantly prolonged compared with those without addition of DHA $(P<0.05)$.

\section{Effects of DHA on $I_{\text {to }}$}

DHA at $0.01 \mu \mathrm{mol} / \mathrm{L}, 0.1 \mu \mathrm{mol} / \mathrm{L}, 1 \mu \mathrm{mol} / \mathrm{L}, 10 \mu \mathrm{mol} / \mathrm{L}$, and $100 \mu \mathrm{mol} / \mathrm{L}$ was applied, respectively. $\mathrm{I}_{\text {to }}$ currents were blocked by DHA in a concentration-dependent manner. Currents were gradually decreased with the increase of DHA concentrations. The current density of $\mathrm{I}_{\text {to }}$ at $+70 \mathrm{mV}$ was $30.1 \pm 7.2 \mathrm{pA} / \mathrm{pF}$ with $\mathrm{DHA}$ at 100 $\mu \mathrm{mol} / \mathrm{L}$. The representative current tracings blocked by $\mathrm{DHA}$ at $100 \mu \mathrm{mol} / \mathrm{L}$ were shown in figures $6 . \mathrm{IC}_{50}$ of DHA on $\mathrm{I}_{\text {to }}$ was fitted with Hill function and calculated by OriginPro 7.5 software, which was $5.3 \mu \mathrm{mol} / \mathrm{L}$.

\section{Discussion}

The typical action potential consists of 5 phases or stages, i.e., $0,1,2,3$, and 4 . The present study has showed that the rat ventricular myocytes don't have the typical action potential morphology. APDs are the shortest in epicardial ventricular myocytes, and repolarization rapidly appears after depolarization, showing no platform phase [17]. The phenomenon of "spike and dome" [18] sometimes can be seen, however, this phenomenon does not appear in endocardial ventricular myocytes. Action potential repolarization in endocardial ventricular myocytes is slow, showing relative standard action potential morphology. The action potential morphologies of mid-cardial ventricular myocytes are between epicardial and endocardial ventricular myocytes $[19,20]$, but action potential repolarization is still rapid, and has the tendency of platform phase compared with the epicardial ventricular myocytes. The reasons why these alterations appear are that there are regional differences of $\mathrm{I}_{\mathrm{to}}$ in epicardial, mid-cardial and endocardial ventricular myocytes. The $\mathrm{I}_{\text {to }}$ channels are the most abundant in rat epicardial ventricular 
Table 1: $\mathrm{APD}_{25}, \mathrm{APD}_{50}$, and $\mathrm{APD}_{90}$ of epicardial, mid-cardial and endocardial ventricular myocytes

\begin{tabular}{ccccc}
\hline & $\mathbf{n}$ & APD25 (ms) & APD50 (ms) & APD90 (ms) \\
\hline Epi & 50 & $3.6 \pm 1.2$ & $10.3 \pm 2.1$ & $46.3 \pm 4.8$ \\
Mid & 58 & $6.4 \pm 1.8$ & $14.7 \pm 2.4$ & $69.4 \pm 8.3$ \\
Endo & 62 & $13.8 \pm 2.1$ & $45.3 \pm 10.2$ & $152.1 \pm 33.4$ \\
\hline Pvalue & & $P<0.05$ & $P<0.05$ & $P<0.05$ \\
\hline
\end{tabular}

Epi, Mid, and Endo represent epicardial, mid-cardial and endocardial ventricular myocytes respectively

myocytes and then in mid-cardial and endocardial ventricular myocytes by turns. The $\mathrm{I}_{\text {to }}$ current densities in epicardial, mid-cardial and endocardial ventricular myocytes were different in this study, which further illustrates that $I_{\text {to }}$ channels of rat ventricular myocytes have regional differences. $I_{\text {to }}$ channels in epicardial myocytes are extremely abundant, and therefore, $I_{\text {to }}$ currents are the largest, which makes action potential repolarization rapid, calcium inflow time and APDs short. In contrast, $\mathrm{I}_{\text {to }}$ channels in endocardial myocytes are few or lack, and therefore, APDs prolong. APA, Vmax, and OS are formed mainly by 0 phase depolarization. Because regional differences of $\mathrm{I}_{\text {to }}$ channels do not affect depolarization of ventricular myocytes, and thus, APA, Vmax, and OS don't have significant differences in epicardial, mid-cardial and endocardial myocytes [21].

The $\mathrm{Ca}^{2+}$-insensitive but 4-aminopyridine-sensitive $\mathrm{I}_{\text {to }}$ currents play a major role in modulating cardiac electrical activity [22]. It underlies phase 1 repolarization, and thus, by setting the voltage of the early plateau phase, it influences activation and inactivation of other plateau currents that control repolarization. It has also been reported in several studies that $\mathrm{I}_{\text {to }}$ channels are potentially important targets for both neuromodulatory control [23] and antiarrhythmic drug actions [24]. These currents have been suggested to contribute significantly to the regional electrophysiological heterogeneity within the ventricular wall, a fact considered to be responsible for T-wave polarity. The heterogeneous distribution of $\mathrm{I}_{\text {to }}$ thus appears to be essential in causing the transmural electrical gradients necessary for proper repolarization of cardiac action potentials. It is expected that changes in $\mathrm{I}_{\text {to }}$ distribution and availability can be expressed in the ECG by typical J-wave and T-wave alterations and may lead to cardiac arrhythmias during evolving heart diseases.

The present study results have showed that there are regional differences of action potentials and $\mathrm{I}_{\text {to }}$ amplitude and morphology of rat epicardial, mid-cardial and endocardial myocytes. Regional differences of action potentials and $I_{\text {to }}$ should be considered when rats are chosen as the experimental animal. We should try to obtain same regional ventricular myocytes to avoid experiment errors when we perform cellular electrophysiological study. Consequently, in this study, we only chose epicardial myocytes to investigate the effects of DHA on action potentials and $\mathrm{I}_{\text {to }}$.

$\omega-3$ PUFAs mainly include DHA and EPA. In order to investigate the mechanisms of $\omega-3$ PUFAs on antiarrhythmias and prevention of sudden death, we performed this experiment to study the effects of DHA on action potential and $I_{t o}$ of rat ventricular myocytes. The reasons that we chose the rats as experimental animal is not only because the rats have many advantages, e.g. cheap, strong vitality, and easily bred, but more impor-

Table 2: Vmax, APA, and OS of epicardial, mid-cardial and endocardial ventricular myocytes

\begin{tabular}{|c|c|c|c|c|}
\hline & $n$ & $V \max (V / s)$ & APA $(m V)$ & OS (mV) \\
\hline Epi & 71 & $228.3 \pm 14.5$ & $110.7 \pm 10.1$ & $31.5 \pm 5.4$ \\
\hline Mid & 63 & $231.2 \pm 13.4$ & $111.9 \pm 9.3$ & $32.4 \pm 6.3$ \\
\hline Endo & 70 & $226.9 \pm 12.8$ & $109.8 \pm 8.9$ & $30.8 \pm 4.8$ \\
\hline$P$ value & & $P>0.05$ & $P>0.05$ & $>0.05$ \\
\hline
\end{tabular}

Epi, Mid, and Endo represent epicardial, mid-cardial and endocardial ventricular myocytes respectively, and Vmax, APA, and OS represent maximal velocity of action potential depolarization, action potential amplitude and overshoot 


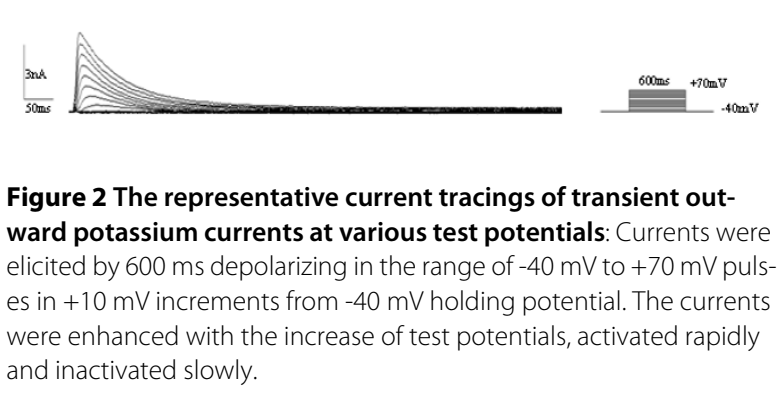

tant is that there are many similar electrophysiological characteristics of rat and the human being's cardiomyocytes $[25,26]$.

After DHA at various concentrations was applied, APDs were gradually prolonged and $I_{t o}$ currents were decreased by degrees with the increase of DHA concentrations. DHA could inhibit $\mathrm{I}_{\text {to }}$ currents, prolong APDs, and extend effective refractory period of myocardial myocytes [27]. The effects of DHA on action potentials and $\mathrm{I}_{\text {to }}$ may be one of its anti-arrhythmia mechanisms.

Figure 6 clearly showed that DHA could inhibit $\mathrm{I}_{\text {to }}$ currents. However, from the morphologic changes of action potentials in figure 5, we found that the morphologic changes of action potentials mainly appeared in phase 2 and phase 3 with the increase of DHA concentrations. In contrast, action potential phase 1 formed mainly by $\mathrm{I}_{\text {to }}$ current efflux didn't have significant changes. This means

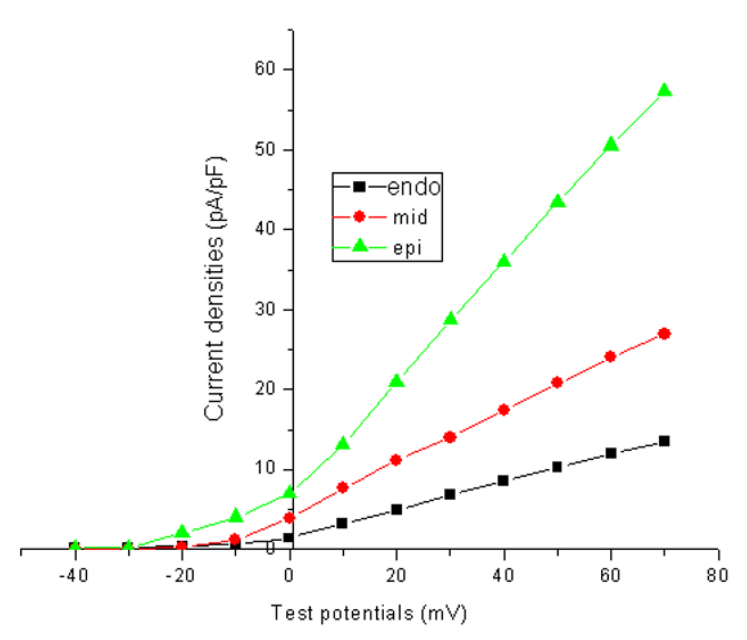

Figure 3 The current-voltage curves of transient outward potassium currents in epicardial, mid-cardial and endocardial ventricular myocytes: Currents in epicardial, mid-cardial and endocardial ventricular myocytes were all enhanced with the increase of test potentials from $-40 \mathrm{mV}$ to $+70 \mathrm{mV}$, whereas currents in epicardial were higher than those in mid-cardial and endocardial at the same test potential, and currents in mid-cardial were larger than those in endocardial.

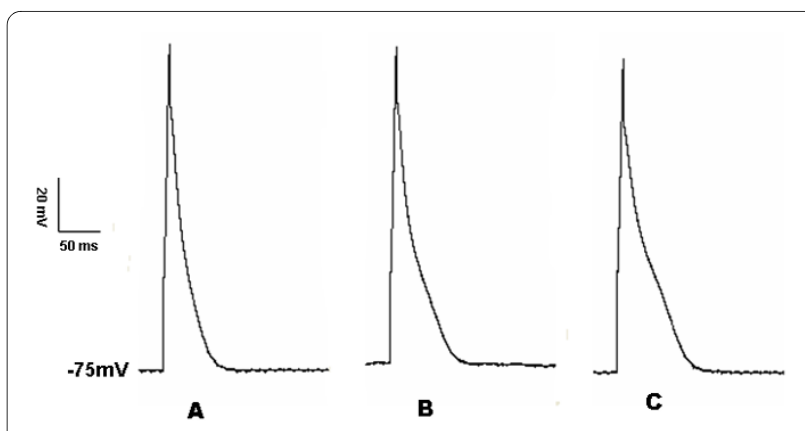

Figure 4 Action potential changes of rat ventricular myocytes at $0.1 \mu \mathrm{mol} / \mathrm{L}$ DHA: A, B, and C were morphologies of action potential when $0.1 \mu \mathrm{mol} / \mathrm{L}$ DHA was applied at $0 \mathrm{~min}, 1 \mathrm{~min}$, and $5 \mathrm{~min}$, respectively. The action potential duration was increased; however, compared with the control $(0 \mathrm{~min})$, the prolongation of action potential duration was less than $15 \%$.

DHA may have the effects on other ion currents in addition to $\mathrm{I}_{\mathrm{to}}$ current.

The present study has some limitations, e.g., we only investigated the effects of DHA on action potentials and $\mathrm{I}_{\text {to }}$ of rat ventricular myocytes. On the other hand, $\omega-3$ PUFAs not only include DHA but also EPA, the electrophysiological effects of EPA on rat ventricular myocytes, and DHA on other ion currents such as $\mathrm{I}_{\mathrm{Na}}, \mathrm{I}_{\mathrm{Ca}-\mathrm{L}}, \mathrm{I}_{\mathrm{K}}$, and $\mathrm{I}_{\mathrm{K} 1}$ are still needed to further study. Only we completely explore the anti-arrhythmia mechanisms of $\omega-3$ PUFAs, we can apply them correctly in clinical practice to prevent and treat cardiovascular diseases [28-32].

\section{Conclusion}

In summary, the present findings obtained by the patchclamp technique have clearly shown that APDs are prolonged, and $\mathrm{I}_{\text {to }}$ currents are gradually reduced with the

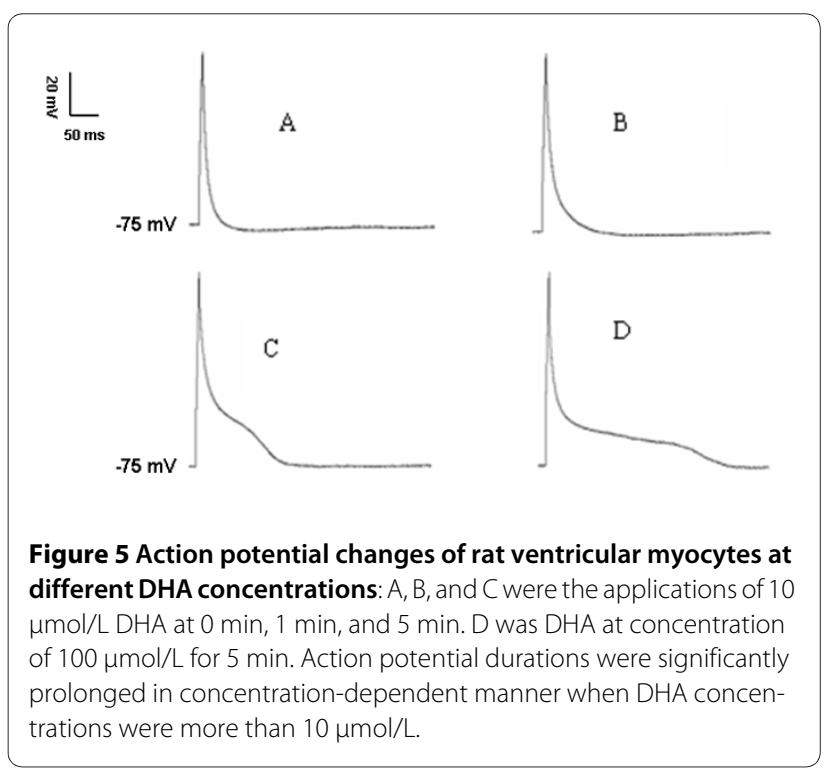




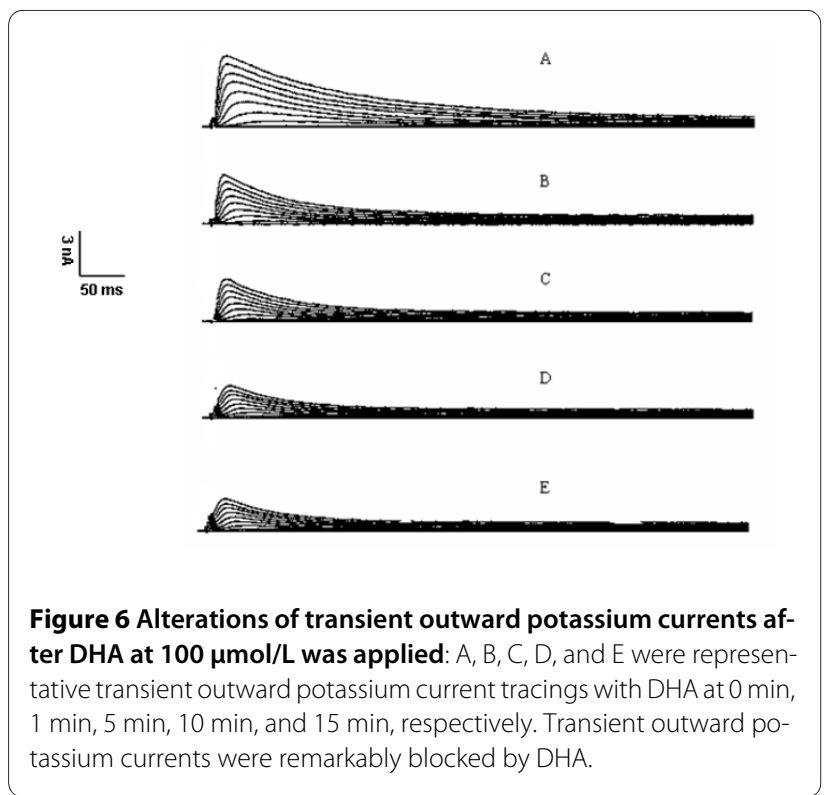

increase of DHA concentrations. Effects of DHA on action potentials and $I_{\text {to }}$ may be one of the important causes of anti-arrhythmias.

\section{Competing interests}

The authors declare that they have no competing interests.

\section{Authors' contributions}

$X R L, X J Y$, and WPP designed research and revised the manuscript; RXW, LPS, SXG, and ZYY performed research; RXW wrote the manuscript; RXW and TG analyzed data. All authors read and approved the final manuscript.

\section{Acknowledgements}

This work was supported, in part, by a grant (CS20010015) from Wuxi Science and Technology Bureau of Jiangsu Province, China. The authors thank Miss Hong-xia Li and Miss Lian-hua Han for their assistance in the preparations of this paper.

\section{Author Details}

'Department of Cardiology, Affiliated Hospital of Nanjing Medical University in Wuxi and People's Hospital of Wuxi City, Wuxi 214023, China, 2Department of Cardiology, First Affiliated Hospital of Kunming Medical College, Kunming 650032, China and ${ }^{3}$ Department of Cardiology, First Affiliated Hospital of Soochow University, Suzhou 215006, China

Received: 5 March 2010 Accepted: 17 April 2010

Published: 17 April 2010

\section{References}

1. Lavie CJ, Milani RV, Mehra MR, Ventura HO: Omega-3 polyunsaturated fatty acids and cardiovascular diseases. J Am Coll Cardiol 2009, 54:585-94.

2. Crumb JR, Munfakh N, Heck HA, Harrison LH: Fatty acid block of the transient outward current in adult human atrium. J Pharmacol Exp Ther 1999, 289:386-91.

3. Wilhelm M, Tobias R, Asskali F, Kraehner R, Kuly S, Klinghammer L, Boehles $H$, Daniel WG: Red blood cell omega-3 fatty acids and the risk of ventricular arrhythmias in patients with heart failure. Am Heart J 2008, 155:971-7.

4. Arshad A, Mandava A, Kamath G, Musat D: Sudden cardiac death and the role of medical therapy. Prog Cardiovasc Dis 2008, 50:420-38.

5. Anand RG, Alkadri M, Lavie CJ, Milani RV: The role of fish oil in arrhythmia prevention. J Cardiopulm Rehabil Prev 2008, 28:92-8.
6. Metcalf RG, Sanders P, James MJ, Cleland LG, Young GD: Effect of dietary $n-3$ polyunsaturated fatty acids on the inducibility of ventricular tachycardia in patients with ischemic cardiomyopathy. Am J Cardiol 2008, 101:758-61.

7. Von Schacky C: Omega-3 fatty acids: antiarrhythmic, proarrhythmic or both? Curr Opin Clin Nutr Metab Care 2008, 11:94-9.

8. He K: Fish, long-chain omega-3 polyunsaturated fatty acids and prevention of cardiovascular disease--eat fish or take fish oil supplement? Prog Cardiovasc Dis 2009, 52:95-114.

9. Smith CE, Freeman LM, Rush JE, Cunningham SM, Biourge V: Omega-3 fatty acids in Boxer dogs with arrhythmogenic right ventricular cardiomyopathy. J Vet Intern Med 2007, 21:265-73.

10. Leaf A: Omega-3 fatty acids and prevention of arrhythmias. Curr Opin Lipidol 2007, 18:31-4.

11. Leaf A: Prevention of sudden cardiac death by $n-3$ polyunsaturated fatty acids. Fundam Clin Pharmacol 2006, 20:525-38.

12. Von Schacky C, Harris WS: Cardiovascular benefits of omega-3 fatty acids. Cardiovasc Res 2007, 73:310-5.

13. Kottke TE, La Wu, Brekke LN, Brekke MJ, White RD: Preventing sudden death with n-3 (omega-3) fatty acids and defibrillators. Am J Prev Med 2006, 31:316-23.

14. Yazawa K, Kaibara M, Ohara M, Kameyama M: An improved method for isolating cardiac myocytes useful for patch-clamp studies. Jap J Physiol 1990, 40:157-63.

15. Tytgat J: How to isolate cardiac myocytes. Cardiovasc Res 1994, 28:280-3.

16. Hamill OP, Marty A, Nether E, Sakmann B, Sigworth FJ: Improved patchclamp techniques for high-resolution current recording from cells and cell-free membrane patches. Pflugers Arch 1981, 391:85-100.

17. Shigematsu S, Kiyosue T, Sato T, Arita M: Rate-dependent prolongation of action potential duration in isolated rat ventricular myocytes. Basic Res Cardiol 1997, 92:123-8.

18. Hulme JT, Orchard CH: Effect of acidosis on transient outward potassium current in isolated rat ventricular myocytes. Am J Physiol Heart Circ Physiol 2000, 278:50-9.

19. Stilli D, Berni R, Bocchi L, Zaniboni M, Cacciani F, Sgoifo A, Musso E: Vulnerability to ventricular arrhythmias and heterogeneity of action potential duration in normal rats. Exp Physiol 2004, 89:387-96.

20. Fauconnier J, Bedut S, Le Guennec JY, Babuty D, Richard S: Ca ${ }^{2+}$ currentmediated regulation of action potential by pacing rate in rat ventricular myocytes. Cardiovasc Res 2003, 57:670-80.

21. Orta-Salazar G, Bouchard RA, Morales-Salgado F, Salinas-Stefanon EM: Inhibition of cardiac $\mathrm{Na}^{+}$current by primaquine. Br J Pharmacol 2002, 135:751-63.

22. Antzelevitch C, Sicouri S, Litovsky SH, Lukas A, Krishnan SC, Di Diego JM Gintant GA, Liu DW: Heterogeneity within the ventricular wall: electrophysiology and pharmacology of epicardial, endocardial, and M cells. Circ Res 1991, 69:1427-49.

23. Fedida D, Braun AP, Giles WR: a1-Adrenoceptors in myocardium: functional aspects and transmembrane signaling mechanisms. Physiol Rev 1993, 73:469-87.

24. Duan D, Fermini B, Nattel S: Potassium channel blocking properties of propafenone in rabbit atrial myocytes. J Pharmacol Exp Ther 1993, 264:1113-23.

25. He JY, Kargacin ME, Kargacin GJ, Ward CA: Tamoxifen inhibits $\mathrm{Na}^{+}$and $\mathrm{K}^{+}$ currents in rat ventricular myocytes. Am J Physiol Heart Circ Physiol 2003, 285:661-8.

26. Bryant $\mathrm{SM}$, Shipsey SJ, Hart G: Normal regional distribution of membrane current density in rat left ventricle is altered in catecholamine-induced hypertrophy. Cardiovasc Res 1999, 42:391-401.

27. Adamantidis MM: Mechanisms of action of class III antiarrhythmia agents. Arch Des Maladies du Coeur et des Vaisseaux 1995, 88:33-40.

28. Xiao YF, Sigg DC, Ujhelyi MR, Wilhelm JJ, Richardson ES, laizzo PA: Pericardial delivery of omega-3 fatty acid: A novel approach to reducing myocardial infarct sizes and arrhythmias. Am J Physiol Heart Circ Physiol 2008, 294:H1 144-52.

29. Den Ruijter HM, Berecki G, Verkerk AO, Bakker D, Baartscheer A, Schumacher CA, Belterman CN, de Jonge N, Fiolet JW, Brouwer IA, Coronel R: Acute administration of fish oil inhibits triggered activity in isolated myocytes from rabbits and patients with heart failure. Circulation 2008, 117:536-44. 
30. Reiner E, Tedeschi-Reiner E, Stajminger G: The role of omega-3 fatty acids from fish in prevention of cardiovascular diseases. Lijec Vjesn 2007, 129:350-5.

31. Jacobson TA: Beyond lipids: the role of omega-3 fatty acids from fish oil in the prevention of coronary heart disease. Curr Atheroscler Rep 2007, 9:145-53.

32. Farzaneh-Far R, Lin J, Epel ES, Harris WS, Blackburn EH, Whooley MA: Association of marine omega- 3 fatty acid levels with telomeric aging in patients with coronary heart disease. JAMA 2010, 303:250-7.

doi: 10.1186/1476-511X-9-39

Cite this article as: Wang et al., Docosahexaenoic acid has influence on action potentials and transient outward potassium currents of ventricular myocytes Lipids in Health and Disease 2010, 9:39

Submit your next manuscript to BioMed Central and take full advantage of:

- Convenient online submission

- Thorough peer review

- No space constraints or color figure charges

- Immediate publication on acceptance

- Inclusion in PubMed, CAS, Scopus and Google Scholar

- Research which is freely available for redistribution

Submit your manuscript at www.biomedcentral.com/submit
() BioMed Central 